\title{
Young to Middle-Aged Adults and Low Education: Risk Factors of Spondylitis Tuberculosis with Neurological Deficit and Deformity at Dr. Hasan Sadikin General Hospital
}

\author{
Adrian F. Ismiarto, ${ }^{1}$ Bambang Tiksnadi, ${ }^{2}$ Arifin Soenggono ${ }^{3}$ \\ ${ }^{1}$ Faculty of Medicine Universitas Padjadjaran, Indonesia, ${ }^{2}$ Department of Orthopedics and \\ Traumatology Faculty of Medicine Universitas Padjadjaran/Dr. Hasan Sadikin General Hospital \\ Bandung Indonesia, ${ }^{3}$ Department of Basic Medicine Faculty of Medicine Universitas Padjadjaran/ \\ Dr. Hasan Sadikin General Hospital Bandung, Indonesia
}

\begin{abstract}
Background: Incidence of tuberculosis has risen again, including extrapulmonary tuberculosis. Spondilitis tuberculosis is one the most commonly encountered which can cause disability and even death. The aim of this study was to evaluate characteristics of spondilitis tuberculosis patients and probable risk factors.

Methods: This was a descriptive, cross sectional study from all medical records of spondylitis tuberculosis patients at Dr. Hasan Sadikin General Hospital from January 2012 to December 2013. Variables evaluated were demographic data, history related to tuberculosis, nutrinutional status, patient's characteristics, and treatments received.

Results: Spondylitis tuberculosis represented $65.6 \%$ of bone and joints tuberculosis. From 78 cases, the male to female ratio was 1.2:1, and mostly found in young and middle-aged adults (79.6\%) between 20-64 years old. Patients' level of education were mostly elementary school (30.8\%) and unemployed. Clinical symptoms were mostly neurological disorders, deformity (kyphotic/gibbus), and tenderness. Predilections sites were thoracal and lumbal vertebrae. Forty eight percents of cases were also sufferring from TB in other organs. Treatments given for these cases were anti tuberculosis drugs $(80.8 \%)$ and operative procedures $(62.8 \%)$.

Conclusions: Most common clinical manifestations are neurologial deficit, deformity, and tenderness; mostly have pulmonary tuberculosis as a comorbid disease; probable risk factors are young and middleaged adults, low education level, and unemployment.
\end{abstract}

Keywords: Deformity, neurological deficit, risk factors, spondylitis tuberculosis

\section{Introduction}

The Tuberculosis (TB) incidence in the developed countries shows a decline in the last half of the 20th century. However, in twelve countries, including Indonesia, there is approximately $75 \%$ of the estimated 2.9 million missed cases which are either not diagnosed or diagnosed but not reported. ${ }^{1}$

The World Heatlh Organization (WHO) data shows the incidence of extrapulmonary TB in Indonesia is also escalating, in the year 2000: 833 cases; 2005: 6,142; 2010: 11,659; 2011: 14,054; and 2012: 15,697.1 A study by Agrawal et al. 2010, stated that vertebral TB constitutes about $50 \%$ of all cases of skeletal TB. ${ }^{2}$

Spondylitis TB is one of the extrapulmonary
TB that is commonly encountered and can cause disability and even death. This disease also has socio-economical impacts as occupation and productivity of patients will be hampered. The purpose of this study was to collect data about spondylitis TB patient's characteristics that was commonly encountered and might have a role in the disease incidence.

\section{Methods}

This was a descriptive cross-sectional study. The data were collected from all medical records of spondylitis TB inpatient patients at Dr. Hasan Sadikin General Hospital from January 2012 to December 2013. The variables analyzed were demographical data (sex, age, educational

Correspondence: Adrian F. Ismiarto, Faculty of Medicine, Universitas Padjadjaran. Jalan Raya Bandung-Sumedang Km. 21, Sumedang, Indonesia Email: no28ro@yahoo.co.id 
level, occupation, residence), chief complaint, TB-related history (BCG immunization, TB contact), history of anti tuberculosis drugs, clinical manifestations, nutritional status, predilection based on diagnosis, comorbidity diseases, and management.

After approval was given by the ethical committee, data were collected, calculated, analyzed, and then presented in the form of table, diagram, or chart.

\section{Results}

One hundred and sixty cases of bone and joint TB were recorded at the inpatient clinic of Dr. Hasan Sadikin General Hospital from January 2012 to December 2013. The total of all spondylitis TB patients recorded in the hospital were 105, however, we could only collected 78 medical records. These data showed that $65.6 \%$ of bone and joint TB were spondylitis TB. The overall case distribution were 50 cases in 2012 and 55 cases in 2013, however, from 78 medical records, 31 cases (39.7\%) occured in 2012 and 47 cases (60.3\%) in 2013

Based on this study, spondylitis TB cases were a little more prevalent in male. Most cases were in the 20-64 years age group. Furthermore, based on educational level,

Table 1 Demographical Data Spondylitis Tuberculosis Patient in 2012-2013

\begin{tabular}{|c|c|c|c|}
\hline & \multicolumn{2}{|c|}{$\mathbf{N}$} & \multirow{2}{*}{ n(\%) } \\
\hline & Male (\%) & Female (\%) & \\
\hline \multicolumn{4}{|l|}{ Age } \\
\hline $0-9$ & $4(5.1)$ & $1(1.2)$ & $5(6.3)$ \\
\hline $10-19$ & $4(5.1)$ & $2(2.6)$ & $6(7.7)$ \\
\hline $20-64$ & $31(39.8)$ & $31(39.8)$ & $62(79.6)$ \\
\hline$\geq 65$ & $3(3.8)$ & $2(2.6)$ & $5(6.4)$ \\
\hline Total & $42(53.8)$ & $36(46.2)$ & $78(100)$ \\
\hline \multicolumn{4}{|l|}{ Educational level } \\
\hline Primary school & & & 30.8 \\
\hline Middle school & & & 11.5 \\
\hline High school & & & 28.2 \\
\hline Bachelor degree & & & 6.4 \\
\hline Diploma & & & 1.3 \\
\hline No data & & & 21.8 \\
\hline \multicolumn{4}{|l|}{ Occupation } \\
\hline Unemployed & & & 43.6 \\
\hline Private employee & & & 19.2 \\
\hline Freelance & & & 16.7 \\
\hline Government employee & & & 6.4 \\
\hline Retired & & & 3.8 \\
\hline No data & & & 10.3 \\
\hline \multicolumn{4}{|l|}{ Residence } \\
\hline Bandung municipality \& regency & & & 56.4 \\
\hline $\begin{array}{l}\text { Outside of Bandung municipality \& regency of West } \\
\text { Java }\end{array}$ & & & 37.2 \\
\hline Outside of West Java & & & 1.3 \\
\hline Total Study Subject & & & 100 \\
\hline
\end{tabular}




\section{Chief Complaint}

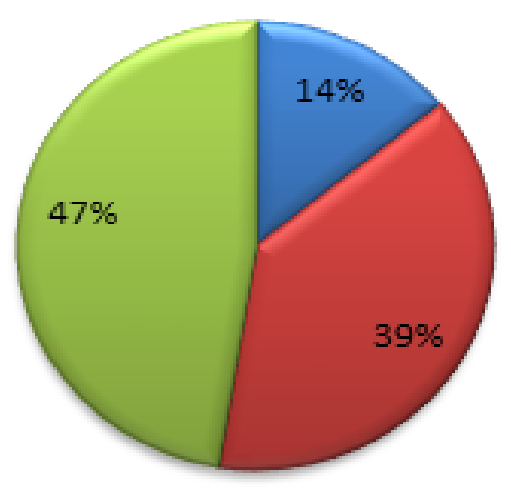

Deformity

口Pain

$\square$ Neurological deficit

Figure 1 Spondylitis Tuberculosis Patient's Characteristics Based on Chief Complaint

primary school was the highest, followed by high school and middle school.

In terms of occupation, most of the patients were unemployed, followed by private employee, and freelancer. Based on residence, most patients lived in Bandung municipality \& regency, followed by Outside of Bandung municipality \& regency of West Java.

The results of the study showed that three most common patient's chief complaints were neurological deficit, followed by pain, and deformity (Figure 1).

Data of TB-related disorders such as BCG immunization, TB contact, and history of anti tuberculosis drugs, were mostly unavailable in the medical records. Therefore, these variables could not be analyzed.

Moreover, the Spondylitis Tuberculosis Patient's Characteristics based on Nutritional status and Clinical Manifestation Nutritional status data were mostly unavailable, therefore this variable could not be analyzed. As for the clinical manifestation, data were collected from the result of physical examinations which indicated that $94.9 \%$ were found to have neurological deficit (sensoric and motoric),

\section{Clinical Manifestations}

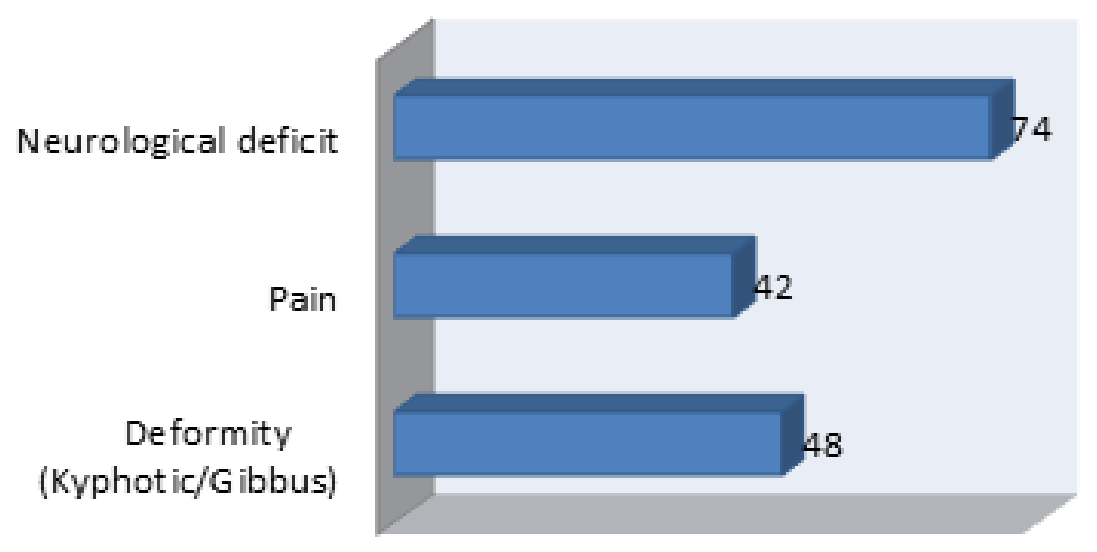

Figure 2 Spondylitis Tuberculosis Patient's Characteristics Based on Clinical Manifestations 


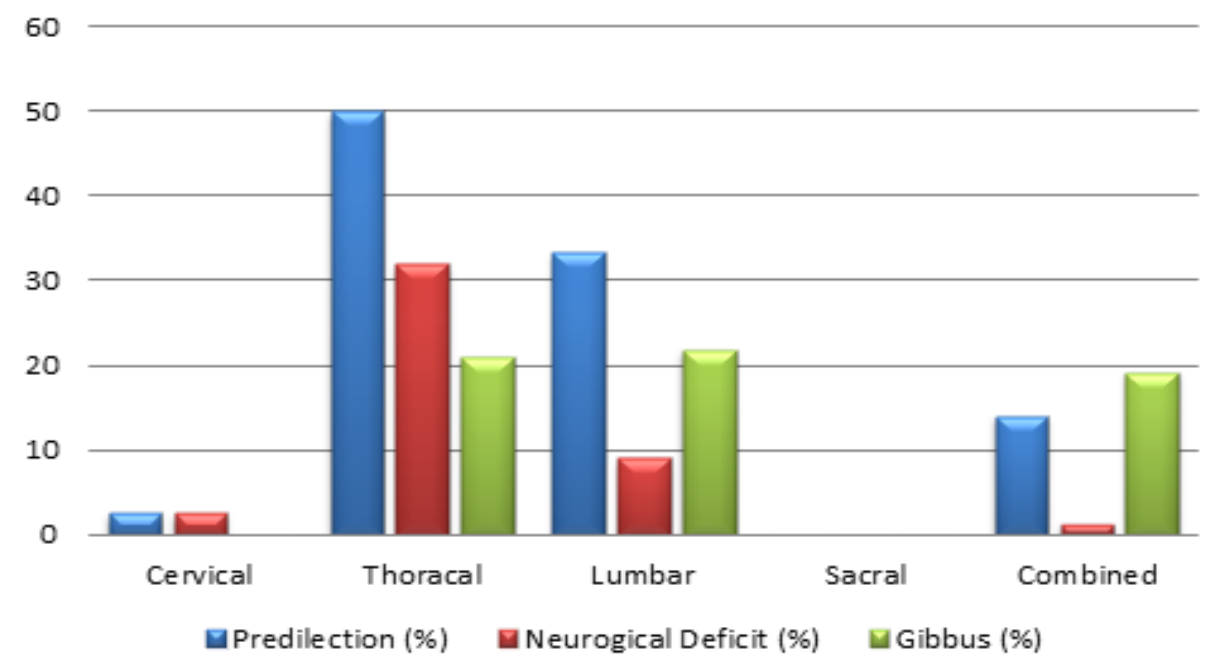

Figure 3 Spondylitis Tuberculosis Predilection and Complication Distribution

followed by $61.5 \%$ of deformity (kyphotic/ gibbus) and $53.8 \%$ of pain (Figure 2).

Furthermore, from 78 medical records of Spondylitis Tuberculosis Predilection and Complication Distribution, this study found the highest predilection was in the thoracic vertebrae, followed by lumbar vertebrae, and combined vertebrae column. While complications such as neurological deficit were found in $44.8 \%$ cases, and gibbus in $61.5 \%$ cases (Figure 3 ).
Additionally, the result of Comorbidity Diseases Characteristics in Spondylitis Tuberculosis Patients showed that 48.7\% (38 cases) of all spondylitis TB also had TB in other organs at the same time. Other comorbidites were also found in various organs (Figure 4).

Study results showed that spondylitis TB patients were given anti tuberculosis agents category I and II and/or operative management (anterior or posterior approach). Anti tuberculosis agents were given to the majority

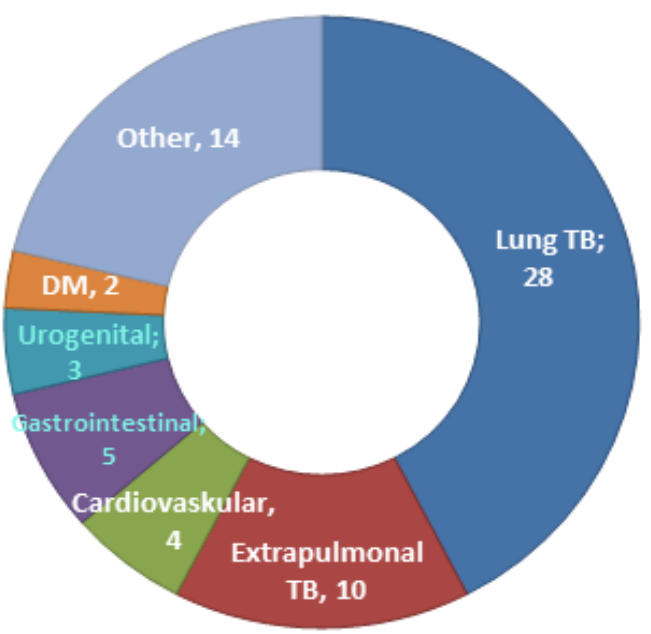

Figure 4 Comorbidity Diseases Characteristics in Spondylitis Tuberculosis Patients 
Table 2 Spondylitis Tuberculosis Patients' Management

\begin{tabular}{lcc}
\hline \multicolumn{1}{c}{ Management } & Total & \% \\
\hline Anti Tuberculosis Agents & 59 & \\
$\quad$ Category I (RHZE) & 1 & \\
$\quad$ (RH) & 1 & \\
$\quad$ HZE) & 1 & 80.8 \\
$\quad$ Category II (2(HRZE)S/(HRZE)/5(HR)3E3) & 1 & 19.2 \\
Anti tuberculosis agents stopped & 63 & \\
Total given anti tuberculosis agents & 15 & \\
Not given anti tuberculosis agents & & \\
Operative & & \\
Posterior approach & 22 & \\
$\quad$ Laminectomy withposterior stabilization & 3 & \\
$\quad$ Laminectomy without posterior stabilization & & \\
Anterior approach & 23 & \\
$\quad$ With posterior stabilization & 1 & \\
$\quad$ Without posterior stabilization & 0 & \\
$\quad$ Anterior \& Posterior approach & 49 & \\
Total given operative management & 26 & \\
Not given operative management & 78 & \\
Total research subjects & & \\
\hline
\end{tabular}

of cases (80.8\%), with some cases undergoing regimen changes. An operative management was given in $62.8 \%$ cases (Table 2 ).

\section{Discussions}

Moreover, the Spondylitis TB cases found at Dr. Hasan Sadikin General Hospital inpatient clinic were 105 cases (65.6\%) which were all bone and joint TB cases. Yehya et al. ${ }^{3}$, also stated that spondylitis TB includes more than $50 \%$ of bone and joint TB.

The total number of cases in male was 42 cases $(53.8 \%)$ and in female was 36 cases (46.2\%), with a ratio of $1.2: 1$. This results were similar to a study by Alavi et al. ${ }^{4}$, that stated male to female ratio is 1.5:1. Khalequezzaman, et al. ${ }^{5}$, also stated in his study, that male to female ratio is $2.5: 1 .{ }^{5}$

Spondylitis TB is a disease that could affect people in any age groups. Middle-aged adults are the most commonly affected age groups. ${ }^{5}$ This study results showed young and middleaged adults (20-64 years old) were the most commonly affected, with 62 cases (79.6\%).
These results were similar to a study by Alavi et al. ${ }^{4}$, that stated spondylitis TB in the endemic area of TB is highest in young adults, however, in developed countries, it is more common in older age. It is probably caused by risk factors such as nutrient deficiency, overcrowding, poor environmental hygiene, etc. which are more common in developing countries. ${ }^{4}$

Higher educational level is assumed to have higher knowledge and awareness about healthy behavior and treatment of the disease. ${ }^{6}$ So far, Indonesia only had a free education program up to middle school level (9 years), which caused the majority of less fortunate people could only obtain education as high as that level. Additionally, Middle school level is still considered as a low educational level. This study also reflected the condition where disease incidences were more common in those with low educational level compared to higher educational level. Primary school level was found to be the highest, as much as $30.8 \%$, followed by high school $(28.2 \%)$ and middle school $(11.5 \%)$. These results were similar to the Case Study of Lung TB Treatment Outcome at 10 Primary Health Care 
facilities in Jakarta from 1996 to 1999, that stated a low educational level would cause lower awareness in maintaining sanitation and environtmental hygiene, which reflects in the majority of TB patients are still carelessly throwing away their sputum. ${ }^{6}$

However, results of this study also showed that the total of patients with high school educational level was the second highest. It proved that a lot of other factors not directly related to education might have a role in the disease. The low education might havecorrelations with difficulties to get a job, and lower income, which caused poverty and living in slums.

Moreover, a TB Prevalence survey in 2004 showed that although $76 \%$ of families have heard about TB and 85\% know TB can be cured, only $26 \%$ could mention two main signs and symptoms of TB. Tuberculosis modes of transmission are understood by $51 \%$ of families and only $19 \%$ know there are free anti tuberculosis drugs.

This study showed that unemployed people were the most common to catch spondylitis TB, which was consistent with the previous assumption.

Fourty four (56.5\%) spondylitis TB patients lived in Bandung municipality \& regency. Second highest was outside of Bandung municipality \& regency, with 29 patients (37.2\%). Patients from other areas in West Java were comparatively few. This could be due to the national health coverage program was not yet implemented in the period of 2012-2013, so that a lot of spondylitis TB cases were still treated in the highest referral hospital. Dr. Hasan Sadikin General Hospital was one example of this. Besides, the uneven distribution of orthopaedics \& traumatology specialists in regional hospitals could also be one of the reasons.

Generally, spondylitis TB patients complained of feeling unwell, prolonged back pain, and in chronic cases, of gibbus deformity. The neurological examination probably showed altered motoric or sensoric functions in the lower extremity. Spastic paraparesis is commonly encountered in spondylitis TB adult patients with thoracal predilection. ${ }^{7}$ Results of this study showed that three most common chief complaints were neurological deficit (sensoric and motoric), as much as $47.4 \%$, followed by pain $(38.5 \%)$, and deformity (14.1\%).

Disease progression of spondylitis TB was slow and insidious. Garg et al. ${ }^{8}$, stated that the disease have variable duration, beginning from months to years, with 4-11 months as the average. Usually, patients seek treatment when intense pain, deformity, or neurological deficit already happened. ${ }^{8}$ It was found similar results in this study: three most common chief complaints were having onset ranging from 2 months to 1 year.

Data from physical examinations showed the most common clinical manifestation was neurological deficit (sensoric and motoric), as highas $94.9 \%, 61.5 \%$ were deformity(kyphotic/ gibbus), and $53.8 \%$ were pain. It is known that one of the spondylitis TB characteristics is destruction of vertebral bodies and disc spaces, which causes anterior wedging and culminate in gibbus formation. ${ }^{8}$ Deformity was the highest clinical manifestation in this study. Other than that, Garg et al. ${ }^{8}$, stated that back pain is the most commonly manifestation that emerges from this disease. Neurological deficit is also a common occurring manifestation of spondylitis TB involving cervical and thoracic vertebrae.

From 78 cases, the highest disease predilection was at the thoracic vertebrae (50\%), followed by the lumbar (33.3\%). The combination of several vertebrae region were found in $14.1 \%$ cases. Sixty one point five percent cases were presented with gibbus, and $44.8 \%$ with neurological deficit.

Results found in this study were similar to Uduma's in 2013, which stated that spondylitis TB commonly affects the lower thoracic and upper lumbar vertebrae. As stated in his study, the lower thoracic region is involved in $40-50 \%$ of cases, $35-45 \%$ cases involve the lumbar region, and 3-9\% cases involve the cervival region. Thoracolumbar junction is stated as the most common spondylitis TB predilection site. ${ }^{9}$

Various comorbidities with spondylitis TB was found in this study, ranging from TB in other organs to other diseases not related with TB. TB in other organs was found in 38 cases, meanwhile other non-TB diseases were found in 27 cases. Lung TB was the most common (35.9\%), the rest were extrapulmonary TB other than spondylitis (miliary TB, meningitis TB, scrofuloderma, polyserositis TB, and lymphadenitis TB). Miliary TB was occasionally caused by bacillemia from the infected bone and joints in middle-aged or elderly people with bone and joint TB. Whereas in cases which comorbid with lung TB, both infections were probably resulted from reactivation caused by decreased systemic immunocompetence. ${ }^{4,10}$

This study showed that for management of this disease, anti tuberculosis drugs and/ 
or operative interventions were used. Anti TB drugs were given in 63 cases (80.8\%), the remaining $19.2 \%$ were not given. The anti TB drugs given were category I and II, with several cases underwent changes of regimen due to drug allergy. Anti TB drugs were not given in those cases with an operative intervention, had contraindications, and patient's decision to go home without consent for release.

An operative intervention was given to 49 cases $(62.8 \%)$, whereas the remaining 26 cases $(33.3 \%)$ were not operated. As many as 25 cases were operated with the posterior approach technique $(22$ with and 3 without posterior stabilization), and 24 cases with the anterior approach (23 with and 1 without posterior stabilization). Patients who did not undergo operation were those without indication, had financial difficulties, had contraindications, and patient's decision to go home without consent for release.

Based on data from this study, it can be concluded that male to female ratio is 1.2:1. Young and middle-aged group, ranging from 20-64 years is the most commonly affected. Based on educational level, the incidence of this disease is more common in lower educated people. Those unemployed are highest on disease incidence. The majority of patients live in Bandung municipality and regency, followed by outside of Bandung municipality and regency of West Java.

The three most common chief complaints are neurological deficit, followed by pain and deformity. While data from physical examinations showed, the most commonly clinical manifestations are neurological deficit (sensoric and motoric), followed by deformity (kyphotic/gibbus), and lastly, pain.

Thoracic vertebrae are the most common predilection sites of the disease, followed by the lumbar and combined vertebrae regions. Fourty four point eight percent of cases are with neurological complications, and $61.5 \%$ with gibbus.

Almost half of the total spondylitis TB cases $(48.7 \%)$ also have TB in other organs at the same time. Other comorbidities beside TB also exist. These results might be caused by several factors, such as lack of awareness about the risk of TB and its complications, so patient's compliance to anti TB drugs given is low. Stigma from the community to TB patients might cause them not to seek treatment. A poor immune level caused by lack of nutrients also might have a role in the disease progression.

Managements given to patients with this disease are anti tuberculosis drugs (category
I and II) and/or an operative intervention (anterior or posterior approach). Anti TB drugs are given in majority of cases $(80.8 \%)$, with several cases undergoing changes in regimen. The operative intervention is given in $62.8 \%$ of cases.

The limitation of this study is the incomplete data concerning the history of BCG immunizations, TB contact, anti TB drugs before hospitalization, and nutritional status including height and weight of patients in the medical records. Thus, these variables cannot be analyzed.

Therefore, it suggests improving the medical record data completion of each patient, so that it can be used as an accurate research material. Furthermore, improving the society's knowledge about lung TB and extrapulmonary TB (including spondylitis TB), by educating the community regarding modes of transmission, disease progression, and treatment is also important, so patients can be diagnosed and treated as early as possible, minimizing disease transmissions and complications. Intensification of the government's TB treatment programs, improving immunization and nutrition programs at primary health centers in the community are also suggested.

\section{References}

1. World Health Organization. Global tuberculosis report 2013. Geneva: WHO; 2013. [cited 2014 March 15]. Available from: http://apps.who.int/iris/ bitstream/10665/91355/1/9789241564656_ eng.pdf.

2. Agrawal V, Patgaonkar PR, Nagariya SP. Tuberculosis of spine. J Craniovertebr Junction Spine. 2010;1(2):74-85.

3. Yehya A, Mathlom Y, Hafez A. Correlation between clinical, radiological and operative findings in management of tuberculous and pyogenic spondylitis. Bull Alex Fac Med. 2010;46(2):177-84.

4. AlaviSM,SharifiM.Tuberculousspondylitis: risk factors and clinical/paraclinical aspects in the south west of Iran. J Infect Public Health. 2010;3(4):196-200.

5. Khalequzzaman S, Hoque $H$. Tuberculosis of spine magnetic resonance imaging (MRI) evaluation of 42 cases. Medicine Today. 2012;24(2):59-62.

6. Ratnasari NY. Hubungan dukungan sosial dengan kualitas hidup pada penderita tuberkulosis paru (TB paru) di balai pengobatan penyakit paru (BP4) Yogyakarta unit minggiran. J Tuberkulosis 
Indonesia. 2012;8:7-11.

7. Solomon L, Warwick D, Nayagam S. Apley's system of orthopaedics and fractures. 9th ed. Boca Raton, FL: CRC Press,Taylor \& Francis; 2010.

8. Garg RK, Somvanshi DS. Spinal tuberculosis: a review. J Spinal Cord Med. 2011;34(5):440-54.

9. Uduma FU, Emejulu JC, Ianafasi EU, Igwebuike VOI. Review of pott's disease with neurological deficit-radiological algorithm and management. International Journal of Medical and Applied Sciences. 2013;2(3):339-46.

10. Yagi O, Kawabe Y, Nagayama N, Shimada M, Kawashima M, Kaneko Y, et al. Bone and joint tuberculosis concurrent with tuberculosis of other organs. Kekkaku. 2007;82(6):523-9. 